\title{
Commentary on "Sonata Form in the Nineteenth-Century Symphony"
}

\author{
BEN DUANE \\ Washington University, St. Louis
}

\begin{abstract}
This commentary compares observational corpus analysis and hypothesis-driven analytical methods, and discusses the methods used in Cannon's "Sonata Form in the Nineteenth-Century Symphony" article.
\end{abstract}

Submitted 2015 December 16; accepted 2016 March 1.

KEYWORDS: sonata form, corpus study, commentary

Stephen Jay Gould, in an essay about paleontology, commented on the balance of theory and observation in science, invoking a natural scientist no smaller than Charles Darwin:

Geology, in the late eighteenth century, had been deluged with a rash of comprehensive, but mostly fatuous, "theories of the earth"-extended speculations about everything, generated largely from armchairs. When the Geological Society of London was inaugurated in the early nineteenth century, the founding members overreacted to this admitted blight by banning theoretical discussion from their proceedings. Geologists, they ruled, should first establish the facts of our planet's history by direct observationand then, at some future time when the bulk of accumulated information becomes sufficiently dense, move to theories and explanation.

Darwin, who had such a keen understanding of fruitful procedure in science, knew in his guts that theory and observation are Siamese twins, inextricably intertwined and continually interacting. One cannot perform first, while the other waits in the wings. (Gould 1995, 147-148)

Yet I imagine Darwin would quickly acknowledge that science relies not only on a mixture of theory and observation, but on the two being combined in different ways. Most studies follow roughly the same format: a hypothesis is formulated consistent with existing theory and evidence, and then that hypothesis is tested by experiment. Occasionally, however, benefits can be had from work that is either mainly theoretical (new explanations of existing evidence) or purely observational (gatherings of data with no particular hypotheses). Indeed, both types of work are, from time to time, essential.

Steven Craig Cannon's article (2016), "Sonata Form in the Nineteenth-Century Symphony,” is almost fully observational. Rather than testing specific hypotheses, Cannon proceeds in an exploratory manner. He gathers a corpus of symphonies, identifies the key and form of each movement, further analyzes movements in sonata form, and then reports a whole host of statistics, much in the spirit of the Geological Society of London in the early 1800s, with its edict of "evidence now, theory later."

Being so observational, Cannon's study sometimes leaves the reader feeling adrift in a sea of results, unsure of their larger significance within sonata theory or symphonic historiography. At other times, however, his data verify non-trivial assertions about style and form from prior authors, such as Horton's (2013) observation that I⿳3 is often replaced with $\mathrm{I}_{4}^{6}$ at the start of the recapitulation (Cannon, 2016,

p.221. And in other cases, Cannon's results suggest potential work for the future. For example, the precipitous decline in the use of repeat signs around 1860 (Cannon, 2016, p.215-216; Table 6) is reminiscent of Hepokoski and Darcy's (2006, p.21) contention that in eighteenth-century sonatas, "repeats were an important feature of sumptuous, high-prestige display of grand architecture" and thereby "celebrated the 'Enlightenment'...culture that makes such an impressive, moving, or powerful art possible.” Might the abandonment of repeats around 1860 correspond with a specific cultural shift away from such ideals? 
Thus, I am inclined to agree with Cannon that his study, exploratory though it is, "should be of use to anyone with an interest in the symphonic repertoire or in nineteenth-century sonata form." (Cannon, 2016, p.222) The article also raises two methodological issues of particular interest in corpus analysis. They are worth discussing, especially in the context of a journal issue on this emerging subfield.

\section{SAMPLE SIZE AND SOPHISTICATION OF MUSIC ANALYSES}

Musical corpus analysis is labor-intensive. The structures of interest to researchers-chords, cadences, phrase boundaries, contrapuntal skeletons lurking beneath florid surfaces-are often neither explicit in the scores nor accurately detectable using existing computational algorithms. Corpus studies, then, often require human analysts to sit down with big piles of scores. But humans can only analyze so quickly, and unless one commands a large team of musical experts, his or her corpora will tend to have one of two shortcomings: they will be small, or they will be analyzed in a simple, time-efficient way. It is a reality of corpus research.

Cannon opted for the latter drawback, performing relatively simple analyses on 282 symphonies and 483 sonata-form movements. While his sample is large and robust, the simplicity of his analyses is sometimes a problem. In particular, his decision not to identify the beginnings of coda sections (Cannon, 2016, p.206) renders many results difficult to interpret, especially with regard to the proportions of movements. Figure 5, for example, illustrates that as the nineteenth century unfolded, expositions became smaller relative to the lengths of their movements. But this trend could actually reflect a change in the proportions of codas. Codas may well have become proportionally longer over the course of the century, and if so, then all other sections, including the exposition, would have become proportionally smaller. The apparent shrinking of expositions, then, might only be an artifact of another change.

In this case, the ambiguity of this result could perhaps be resolved by taking a sample of the sample - that is, by extracting a random subset of, say, 50 movements from Cannon's 483 . These 50 movements could be analyzed in more detail and their codas identified. While the sample would be smaller, the results might indicate whether codas expanded over time, expositions shrank, or both.

\section{SAMPLING THE REPERTOIRE VS. SAMPLING THE CANON}

Cannon should be commended for the systematic manner in which he populated his corpus. Rather than choosing pieces willy-nilly, he gathered "all nineteenth-century symphonies whose scores were either held in the Marvin Duchow Music Library at McGill University, or were available online from the Petrucci Music Library, run by the International Music Scores Library Project [IMSLP].” The author's own predilections certainly had no impact on which symphonies were and were not included.

Yet his sources-McGill's library and the IMSLP database-are themselves undoubtedly biased toward the usual canon of Western art music. Not every historical composer receives equal attention from modern listeners and performers, scholars and conductors. Indeed, most are entirely forgotten. A precious few enjoy the status of a Hummel or a Spohr. Fewer still hold the rank of a Schubert or a Brahms. Any corpus gathered from collections like those of McGill and IMSLP surely reflects these modern preferences - and it surely favors a tiny handful of composers in a most enormous way. In other words, a dataset like the author's is a sample of the modern canon, not the musical practices of the nineteenth century.

This is a valid method of sampling — stylistic trends within the modern canon are worth studying. But one must be careful not to generalize too much beyond the canon. The author, for example, suggests that "during the nineteenth century, symphonies did not appear at a steady rate," since the corpus contained "more symphonies from the beginning and end of the [century] but fewer from the middle." (Cannon, 2016, p.4) This result, however, may not reflect the actual output of composers of the time. The shortage of midcentury symphonies at McGill and IMSLP might only reflect a shortage of mid-century symphonic composers who made it into the canon.

The author, of course, points out that other scholars have discovered a similar scarcity of symphonies in the middle of the nineteenth century (Cannon, 2016, p.208. He also connects this decline in compositional output to factors both artistic (the genre's "crisis" in the 1840-60s; Cannon, 2016, p.209 and geopolitical (the preponderance of wars in the same period; Cannon, 2016, p.208. His finding, then, might 
be part of a larger picture of converging evidence. On its own, however, this result should not be overgeneralized, since it may be confounded by the effects of canonization.

\section{REFERENCES}

Cannon, S. C. (2016). Sonata Form in the Nineteenth-Century Symphony. Empirical Musicology Review, 11(2), 204-224. https://doi.org/10.18061/emr.v11i2.4956

Gould, S. J. (1995). Dinosaur in a Haystack Dinosaur in a Haystack: Reflections in Natural History (pp. 147-158). New York: Harmony Books. https://doi.org/10.4159/harvard.9780674063426

Hepokoski, J., \& Darcy, W. (2006). Elements of sonata theory: Norms, types, and deformations in the late eighteenth-century sonata. New York: Oxford University Press.

https://doi.org/10.1093/acprof:oso/9780195146400.001.0001

Horton, J. (2013). Tonal Strategies in the Nineteenth-Century Symphony. In J. Horton (Ed.), The Cambridge Companion to the Symphony (pp. 232-267). Cambridge: Cambridge University Press. https://doi.org/10.1017/CCO9781139021425.012 